\title{
Snapshot of Non-Inclusive Growth: Evidence from Philippine Employment Trends in 2001-2009
}

\author{
Ronald U. Mendoza*, Padmini Mahurkar \\ Asian Institute of Management (AIM) Policy Center, Makati City, Philippines \\ Email: rumendoza@aim.edu
}

Received September 4, 2012; revised October 8, 2012; accepted October 17, 2012

\begin{abstract}
This article briefly examines the Philippines' pattern of job creation during the period 2001-2009 in order to help explain why growth during this period failed to translate into poverty reduction. An analysis of disaggregated employment and sectoral output data provides a much more nuanced picture of the types and sectors of jobs created during the last decade. The empirical evidence suggests that employment creation was inadequate, and skewed in favor of high skilled workers even across industries. Based on these findings, promoting inclusive growth in the Philippines requires a robust job creation strategy in order to meet the growing labor force, along with mechanisms to ensure skill upgrading and better skills matching (notably for the young) as well as efforts to bring even lower skilled workers into the formal sector.
\end{abstract}

Keywords: Inclusive Growth; Employment Elasticity of Growth; Informality

\section{Introduction}

In the last decade, Philippine economic growth averaged 4 - 5 percent per annum - very respectable based on this country's historical growth performance. Nevertheless, poverty remained sticky during that period. About 20 26 percent of the population (depending on the estimation method) remained mired in poverty [1]. Most analysts note that Philippine economic growth in the last decade was far from inclusive [2-4].

Notwithstanding the important role of entrepreneurship in uplifting the lives of the poor, poor and low income families derive most of their income from employed work. Many studies have examined the links across economic growth, employment and poverty reduction [5-9]. Developing country strategies to promote inclusive growth and development typically prioritize job creation that is, among other goals, both: 1) adequate (Everyone who wants a job can get one) and 2) inclusive (Poor and low income people are also able to find decent work) [2].

In order to shed light on why Philippine growth in the last decade was not inclusive, this study will undertake an empirical analysis of the country's employment creation pattern using industry- and employment-specific data during the 2001-2009 period. The analysis of disaggregated employment and sectoral output data provides a much more nuanced picture of the types and sectors of

\footnotetext{
"Corresponding author.
}

jobs created during the last decade. The empirical evidence suggests that employment creation was inadequate, and skewed in favor of high skilled workers even across industries. These findings suggest that promoting inclusive growth in the Philippines requires a robust job creation strategy in order to meet the growing labor force, along with mechanisms to ensure skill upgrading and better skills matching (notably for the young) as well as efforts to bring even lower skilled workers into the formal sector.

\section{Brief Review of Literature}

In an ideal world economic growth would be attended by job creation that is both adequate and inclusive. In this manner growth could more easily translate into poverty reduction, and perhaps also mitigate inequality. In reality market forces tend to marginalize poor and low income workers in the labor market for various reasons. First, poor workers are often much less skilled (i.e. due to lack of education and training). This is often combined with various vulnerabilities of living in poverty, such as poor health and poor nutrition, as well as forces related to discrimination and social marginalization. These factors, among many others, conspire to disempower those who live in poverty, making it much more difficult for them to secure decent work. Without help, they are likely to be far less competitive in terms of securing decent work $[6,10]$. 
In addition, the formal sector may not generate enough employment to accommodate the bulk of the population, thus relegating many to the informal sector. Job creation could also be broadly inadequate, and it could also be anemic where it counts for the poor - in terms of weaker growth among less skilled jobs. In a modernizing economy, it would not be surprising to see robust job creation in industries that prioritize high-skilled workers (e.g. business process outsourcing, information technology, medical tourism). Finally, a large informal economy could reflect various market and governance failures, so that entrepreneurs and workers are driven into informality $[7,11]$.

Within Asia, South Asian countries' and the Philippines' economic growth rate has not kept pace with the East and South East Asian (ESEA) countries in the past few decades. The latter have had remarkable success in reducing poverty, and it is useful to draw some observations from their success in job creation and poverty alleviation. For example, in Thailand, over the period 1980 to 2002 there was initially a sharp fall in the poverty levels, followed by a setback during the crisis years of 1996-1998. This was then followed by a period of recovery until 2002. Poverty reduction in Thailand was achieved through a combination of high growth, productive employment and lower inequality. Flexibility in employment allowed for economic growth and poverty levels to reach the pre crisis levels.

Thailand's experience is of the virtuous cycle of growth leading to poverty reduction via growth in employment with rising productivity and reduced poverty [12]. In most of the ESEA countries, in the early decades of $60 \mathrm{~s}, 70 \mathrm{~s}$ and $80 \mathrm{~s}$, growth was driven by a labor intensive manufacturing sector. The capital intensive trend was consolidated only in the 1990s. On the other hand, in South Asian countries like India, Pakistan and Sri Lanka, growth has not been labor intensive. Some attribute the substantial difference in poverty reduction between South Asia and ESEA countries to this difference in job creation $[5,8,13]$.

Studies analyzing disaggregated data on employment point to various imbalances in the quality of employment. One points to 'Primary vs. Secondary Sectors' to distinguish between high paying union jobs and lower paying non unionized jobs. Another identifies "Insiders vs. Outsiders" to distinguish between the urban dwellers (insiders) and rural migrants (outsiders). "Good jobs" vs. "Bad jobs" are also labels used to distinguish between formal and informal work in a number of developing countries, noting that earnings are consistently lower and working hours longer in the informal sector. Some studies have also distinguished between rationed upper tier activities and low entry barrier activities which cut across both formal and informal sectors $[14,15]$.
While these studies differ in their detail, they share some common findings. First, the existence of two or more sectors with different wage setting mechanisms with limited upward mobility for workers from the less productive sectors. Second, segmented labor markets are prevalent throughout the developing economies of the world and these markets in turn imply several policy challenges. The overall rate of economic growth is likely to be lower in more segmented labor markets because of the inability of participants to adapt to changing job trends.

As GDP starts to rise and jobs are created there has to be a sufficient supply of labor for industry. Due to segmented markets, labor cannot be deployed rapidly to the sectors where it is needed. Further, if wages rise in one sector, they do not rise in the others and so growth does not impact the poor unless jobs in that sector grow where the poor are located. This might help explain the widely varying job creation and poverty reduction results even within countries [4].

And if the informal sector is characterized by low wages and poor productivity, then poverty alleviation may not occur even as more jobs are created. Large numbers of working poor are a common feature of many developing countries with massive informal economies. Understanding these schisms in the labor market-across sectors, job types and implied skill content, and arearequires a much more nuanced approach in the monitoring and analysis of employment patterns. That, in turn, could help inform a much more nuanced policy intervention mix.

\section{Data}

The disaggregated employment and sector output data is sourced from the Philippines Department of Labor, Bureau of Labor Statistics over the period 2001-2009. This allows us to go beyond the over-all economy in calculating the employment elasticity - instead focusing on predetermined occupational categories with implied skill requirements on a per sector basis. The Philippines Department of Labor categorizes data on the basis of skill type or occupational class. Those employed are classified as:

1) Officials of Government and Special Interest Organizations, Corporate Executives, Managers, Managing Proprietors, Supervisors;
2) Professionals;
3) Technicians;
4) Clerks;
5) Sales and Service Workers;
6) Farmers, Forestry Workers and Fishermen;
7) Trades and Related Workers;
8) Plant and Machine Operators and Assemblers; 
9) Laborers and Unskilled Workers.

The data is obtained for each sector from the Department of Labor, Yearbook of Labor Statistics 2010. These broad job categories could be analyzed based on their implied skill requirements. Categories 1 - 4 can be classified as "high skilled", 5 - 8 as "medium skilled" and 9 as "low skilled". If we consider that poor and low income workers generally tend to be less skilled, then these implied skill categories could also be used to gauge how "pro-poor" job creation patterns are. This categorization could also be validated by looking at the wages data, which confirms that categories with higher implied skills also command higher average wages (Table 1).

It is important to note that in developing countries mobility between these various classes of employment remain a major policy challenge. There are bottlenecks that do not allow a smooth flow between formal and informal sectors of the labor force. Finally, data on sectoral real GDP over the period 2001-2009 is obtained on the basis of the three sectors, Agriculture (i.e. Agriculture, Fishing and Forestry), Industry (i.e. Mining and Quarrying, Manufacturing, Construction, Electricity, Gas and Water Supply) and Services (i.e. Transport, Storage, Communications, Retail Trade, Financial Intermediation, Real Estate, etc.).

\section{Empirical Model and Results}

In its simplest form, the employment elasticity of growth $(E)$ is defined as the percentage change in employment $(L)$ to a percent change in GDP $(Y)$ :

$$
E=\Delta L / \Delta Y
$$

This is a general measure of the extent to which GDP growth coincides with job creation. Drawing on the approach in the literature, we turn to a double log linear equation $\ln Y=f(L, D)$ where $L$ is labor, $Y$ is output, and $D$ refers to dummy variables representing sectoral influences on the equation $[16,17]$.

$$
\begin{aligned}
\ln L= & \beta_{1} \ln \text { Sector GDP }+\beta_{2} \ln \text { Year } \\
& +\beta_{3} \text { Dummy for Industrial Sector } \\
& +\beta_{4} \text { Dummy for Services Sector }+\varepsilon
\end{aligned}
$$

The results (presented in Table 2) are striking, and they provide further evidence behind why Philippine growth in the 2000s failed to produce stronger poverty reduction results. First, the high skilled employment elasticity of growth was negative but not statistically significant. On the other hand, the medium skilled employment elasticity of growth was positive and significant. That result suggests that a 1 percentage point increase in growth is linked to a 1.3 percentage points increase in employment among medium skilled workers.

\begin{tabular}{|c|c|c|}
\hline All Occupations & Ave Wages (Php) & Ave Wages (US\$) \\
\hline $\begin{array}{l}\text { 1) Officials of Government, } \\
\text { Corporate Executives, } \\
\text { Managers, Proprietors and } \\
\text { Supervisors }\end{array}$ & 589.77 & 11.6 \\
\hline 2) Professionals & 519.62 & 10.22 \\
\hline $\begin{array}{l}\text { 3) Technicians and Associate } \\
\text { Professionals }\end{array}$ & 374.09 & 7.36 \\
\hline 4) Clerks & 305.54 & 6.01 \\
\hline 5) Sales and Service Workers & 217.9 & 4.29 \\
\hline $\begin{array}{l}\text { 6) Farmers, Forestry Workers } \\
\text { and Fishermen }\end{array}$ & 144.06 & 2.83 \\
\hline 7) Trades and Related Workers & 233.09 & 4.59 \\
\hline 8) Plant and Machine Operators & 253.15 & 4.98 \\
\hline $\begin{array}{l}\text { 9) Laborers and Unskilled } \\
\text { Workers }\end{array}$ & 138.76 & 2.73 \\
\hline
\end{tabular}

The last outcome raises some cause for concern. The
Table 1. Average daily wages for all occupations 2001-2009 (in US dollars and Philippine pesos).

Source: Bles.dole.gov.ph (Department of Labor, Republic of the Philippines).

Table 2. Regression results on the employment elasticity of sector growth by implied skill requirement.

\begin{tabular}{ccccc}
\hline Variables & Hypothesis & High Skill & Medium Skill & Low Skill \\
\hline GDP by & $\beta_{1}>0$ & $\begin{array}{c}-0.3102 \\
(0.419)\end{array}$ & $(0.292$ & -1.09 \\
Industry & & & & $(0.009)^{*}$ \\
& & 0.05311 & -0.0549 & 0.0843 \\
Year & $\beta_{2}>0$ & $(0.005)^{*}$ & $(0.000)^{*}$ & $(0.000)^{*}$ \\
& & 1.908 & -1.858 & -0.5440 \\
Industry & $\beta_{3}>0$ & $(0.000)^{*}$ & $(0.000)^{*}$ & $(0.130)^{*}$ \\
(Dummy) & & 4.046 & -2.038 & 0.7258 \\
Services & $\beta_{4}>0$ & $(0.000)^{*}$ & $(0.000)^{*}$ & $(0.189)^{*}$ \\
(Dummy) & & -97.38 & 101.6 & -145.9 \\
Constant & $\alpha>0$ & $(0.003)^{*}$ & $(0.003)^{*}$ & $(0.000)^{*}$ \\
Obs. & & 27 & 27 & 27 \\
$\mathrm{R}^{2}$ & & 0.9988 & 0.9943 & 0.9930 \\
\hline
\end{tabular}

"Significant at $5 \%$.

low skilled employment elasticity of growth was negative and statistically significant, suggesting that every 1 percentage point increase in growth is associated with a 1.1 percentage points decline in low skilled employment.

It implies that the pattern of growth across the main sectors of the economy appears to create jobs primarily for the better skilled — notably medium skilled —workers. If this trend continues, unemployment amongst the least skilled (and therefore the poorest sections of society) could be exacerbated over time.

Perhaps one way to mitigate this is through skills up- 
grading so that low skilled workers are able to compete more effectively for medium skilled employment opportunities, which is where the employment elasticity of growth pattern is more accommodating. It is more likely, however, that low skilled workers in the formal sector will be edged out and funneled downward to the informal sector.

\section{Conclusions}

The past decade of relatively more robust growth in the Philippines has not translated into a comparably robust poverty reduction pattern. Various factors likely conspire to produce this result; and this study sheds light on those reasons related to the country's employment creation patterns. Based on an empirical analysis of the country's employment creation pattern using industry- and employment-specific data during the 2001-2009 period, this study finds evidence that employment creation was not only inadequate. More critically it was, on average, skewed in favor of more skilled-and notably medium skilled-workers across Philippine industries.

Various studies provide further evidence that jobs in the middle skill levels have grown with the Philippine economy, partly borne out of the impressive growth in the services sector. The agricultural, and to some extent also the manufacturing sector, both tend to be much more egalitarian in their initial skill requirements, yet these broad sectors have not grown as aggressively as the services sector.

Thus, the "socio-economic ladder" through employment is discontinuous-low skilled workers do not have the agricultural and manufacturing sectors as a stepping stone towards transitioning into the medium-skilled services and other sectors. Recent analyses point to the "leapfrogging" of the Philippine economy into services, so that the economy is walking on only one leg (while the other leg, manufacturing, is still largely lagging) [1822].

In order to transition the labor force upward, into the formal sector and into more skilled and better paying jobs, policymakers will need to consider an industrial mix whose over-all pattern is conducive to a more inclusive transition. Quality and quantity of jobs created are both important, but so too would the inclusiveness of the over-all job creation pattern. Policies to boost human capital and upgrade skills for the vast majority of poor and low income workers could serve as ladders out of the less skill intensive and informal sector.

In addition, policies to enhance the productivity and dynamism of sectors where most of the poor and low income population are presently located and engaged (or put different, where most of them could be relatively more easily engaged, as compared to higher skilled sec- tors) could help facilitate a more inclusive growth and industrial transition.

\section{REFERENCES}

[1] A. Balisacan, "What Does It Really Take to Move the Philippines out of Poverty?" Presentation to the Mindanao Bridging Leaders Program, 2011.

[2] C. Habito, "An Agenda for High and Inclusive Growth in the Philippines," Asian Development Bank, Manila, 2010. http://www.adb.org/documents/reports/agenda-high-inclu sive-growth/agenda-high-inclusive-growth.pdf

[3] G. Sicat, "Spotlighting on High Economic Growth, Employment of the Poor, and Poverty Reduction: A Three Pronged Strategy," Discussion Paper, University of the Philippines School of Economics, Quezon City, 2010.

[4] H. Son, "Human Capital and Economic Growth," Asian Development Bank, Manila, 2009.

[5] C. Ernst and J. Berg, "The Role of Employment and Labor Markets in the Fight against Poverty," International Labour Organization, Geneva, 2009.

[6] B. Guha-Khasnobis and R. Kanbur, "Informal Labour Markets and Development," Palgrave MacMillan, New York, 2006.

[7] B. Guha-Khasnobis, R. Kanbur and E. Ostrom, "Linking the Formal and Informal Economy: Concepts and Policies," Oxford University Press, Oxford, 2006. doi:/10.1093/0199204764.001.0001

[8] K. Hull, "Understanding the Relationship between Economic Growth, Employment and Poverty Reduction," Organisation for Economic Co-operation and Development, Paris, 2009.

[9] H. Kohli, A. Sharma and A. Sood, "Asia 2050: Realizing the Asian Century," Asian Development Bank, Manila, 2010.

[10] D. Ghai, "Decent Work: Concepts and Indicators," International Labor Review, Vol. 142, No. 2, 2003, pp. 114145. doi:/10.1111/j.1564-913X.2003.tb00256.x

[11] G. Perry, et al., "Informality: Exit and Exclusion," World Bank, Washington DC, 2007.

[12] M. Krongkaew, C. Suchittra and I. Nititithanprapas, "Economic Growth, Employment, and Poverty Reduction Linkages: The Case of Thailand," International Labour Organization, Geneva, 2006.

[13] R. Islam, "Pattern of Economic Growth and Its Implication for Employment," International Labour Organization, Geneva, 2009.

[14] T. Avirgan, L. J. Bivens and S. Gammage, "Good Jobs, Bad Jobs No Jobs: Labor Markets and Informal Work in Egypt, El Salvador, India, Russia and South Africa," Economic Policy Institute, Washington DC, 2005.

[15] G. Fields, "A Guide to Multisectoral Labor Market Models," World Bank, Washington DC, 2009.

[16] R. Brooks, "Why Is Unemployment High in the Philippines?" IMF Working Paper 02/23, International Monetary Fund, Washington DC, 2002. 
http://www.imf.org/external/pubs/ft/wp/2002/wp0223.pdf

[17] I. Islam and S. Nazara, "Estimating Employment Elasticity for the Indonesian Economy: A Technical Note on the Indonesian Labour Market," International Labour Organization, Geneva, 2000.

[18] F. Aldaba and R. Hermoso, "Employment Creation: A Strategic Concern for the Philippine Economy," Ateneo de Manila University, Manila, 2009.

[19] N. Usui, "Transforming the Philippine Economy: Walking on Two Legs," ADB Working PAPER 252, Asian Development Bank, Manila, 2011.
http://www.adb.org/Documents/Working-Papers/2011/Ec onomics-WP252.pdf

[20] D. Canlas, 2008. "Philippine Labor Market Outcomes and Scenarios: 2000-2015," ILO Asia Pacific Working Series.

[21] J. Felipe and L. Lanzona, "Unemployment, Labor Laws, and Economic Policies in the Philippines," Asian Development Bank, Manila, 2005.

[22] E. Gropello, T. Hong, and P. Tandon, "Skills for the Labor Market in the Philippines," World Bank, Washington DC, 2010. doi:/10.1596/978-0-8213-8489-3 